\title{
Descortinando o acesso aos serviços de saúde na perspectiva da interdisciplinaridade: debate de ideias
}

| ${ }^{1}$ Leyla Gomes Sancho, ${ }^{2}$ Neide Emy Kurokawa Silva I

Resumo: O objetivo deste estudo é evidenciar, sob o olhar interdisciplinar da Economia, Política, Direito e Socioantropologia, a conformação do conceito de acesso, particularmente o relacionado ao serviço de saúde. Consideramos não apenas a concepção e a ressignificação dos conceitos de oferta, demanda, equidade e necessidade de saúde advindas desses campos disciplinares, mas assumimos a hipótese de que, independentemente do setor público ou privado, o acesso, mais do que uma questão relativa à oferta, deve vislumbrar inicialmente as necessidades ditas "invisíveis", caso seja internalizada a ideia de que o processo saúde-doença não prescinde de incluir outros determinantes para sua compreensão. A partir de revisão de literatura nacional e internacional das últimas cinco décadas, identificaram-se estudos que contemplaram a diversidade dos olhares em relação ao objeto de estudo. De acordo com distintos paradigmas, numa perspectiva histórica e contextual, evidenciou-se que a compreensão e a efetivação do acesso aos serviços de saúde reclamam abordagens interdisciplinares, referendando o Estado como provedor de políticas e ações organizadas que culminem em mudança no estado de saúde e na qualidade de vida do sujeito.

> Palavras-chave: acesso; serviços de saúde; interdisciplinaridade; formação de conceito.

\author{
1 Professora adjunta da área \\ de Políticas e Planejamento em \\ Saúde do Instituto de Estudos \\ em Saúde Coletiva. Endereço \\ eletrônico: leylasancho@ \\ gmail.com \\ 2 Professora adjunta da área de \\ Ciências Sociais e Humanas do \\ Instituto de Estudos em Saúde \\ Coletiva da Universidade \\ Federal do Rio de Janeiro. \\ Endereço eletrônico: neks@ \\ uol.com.br
}

Recebido em: 22/08/2012 Aprovado em: 04/02/2013 


\section{Introdução}

Os sistemas de saúde têm adquirido, na contemporaneidade, crescente importância política, econômica e social. A exteriorização das necessidades e demandas de saúde das famílias às instituições, públicas ou privadas, impõe um necessário exame interdisciplinar das práticas que envolvem a saúde. A natureza e a extensão do direito à saúde e o efetivo acesso a bens e serviços, quer quando tomados como mero investimento em capital humano, quer enquanto vetores em si, de maximização de bem-estar individual e social, passam a ser objeto não apenas de análises políticas e econômicas, mas da interseção destas com as de outras disciplinas das Ciências Humanas e Sociais.

Tem sido a tônica nas agendas de debate das últimas décadas analisar o acesso e a utilização de serviços entre grupos sociais definidos por status sócioocupacional e de saúde, bem como sua conexão com a oferta e a demanda por cuidados de saúde, sob o enfoque da relação entre consumo e consumidor. Embora o senso comum indique que o acesso aos serviços de saúde tem sido dado apenas por uma mera expansão da oferta, numa perspectiva econômica não se podem desconsiderar nesse tipo de análise outros "olhares" disciplinares e, em decorrência disso, outras interpretações que permeiam a compreensão do acesso aos serviços e da satisfação das necessidades em saúde.

O tema do acesso aos serviços e da satisfação das necessidades de saúde tem sido, em grande medida, alavancado pela disciplina da Economia, por meio dos conceitos de oferta e demanda. No entanto, e até mesmo como consequência da explicação e interpretação ampliada dos determinantes sociais do processo saúde-doença-cuidado de Dahlgren e Whitehead (1991, p.314), outras acepções disciplinares e conceitos subjacentes sobressaem nessa discussão. Processar essa análise interdisciplinar supõe, como substrato primordial, não só a decodificação dos conceitos subjacentes - equidade, oferta, demanda e necessidade em saúde implicados no bojo do objeto de interesse deste estudo de acordo com diferentes acepções de cada disciplina, mas também justificar as múltiplas dimensões de análise e os diferentes modelos teóricos explicativos ou interpretativos sobre o acesso aos serviços de saúde.

Não obstante as premissas, este estudo, ao contextualizar e proceder a uma ressignificação através de diferentes concepções teóricas dos inerentes conceitos da dual e não mutuamente exclusiva relação entre o acesso aos serviços de saúde 
e a satisfação das necessidades em saúde, descortina-a através de diferentes olhares (inter) disciplinares.

\section{A construção do texto}

A construção de um texto é um momento de ressignificação hermenêutica, pois este surge a interação do sujeito com o objeto de sua investigação, ao se confrontarem o conhecimento do pesquisador, o senso comum e o conhecimento científico preexistente propriamente dito (JESUS; ASSIS, 2010).

Tomando como subsídio estudos sobre o objeto de interesse realizados ao longo das últimas cinco décadas - o acesso aos serviços de saúde e a decorrente satisfação das necessidades de saúde -, buscou-se evidenciar, a partir das definições sobre o termo "acesso" ao longo desse período, a conformação das dimensões específicas a si atreladas. Em grande medida, elas representam a incorporação de diferentes determinantes e condicionantes, pelos quais é possível margear as interpretações do termo, explicá-lo e compreendê-lo sob uma perspectiva histórica, contextual ou circunstancial (ANDERSON, 1973; ASSIS; VILA; NASCIMENTO, 2003; TRAVASSOS; MARTINS, 2004). Sustenta-se a tese de que, diante de dada realidade construída, tanto pela subjetividade como pela objetividade do sujeito, e dado seu caráter complexo, o conceito de acesso transcende ser um simples elemento de análise e passa a ser uma categoria de análise (GIOVANELLA; FLEURY, 1996). Quando circunscrito aos serviços de saúde, tampouco se atém a uma mera oferta.

A escolha a priori dos conceitos de equidade, oferta, demanda e necessidade de saúde tem como premissas o fato de estarem implicados nas teorias ou fundamentos de áreas do conhecimento como Economia, Política, Direito e Antropologia que não só compõem o campo da Saúde Coletiva, como são afetos à temática em questão. Além disso, são também conceitos permanentemente submetidos a um processo de ressignificação, porque há um imbricar taxonômico entre eles, segundo o qual, de acordo com dada leitura de determinado conceito, os demais ou são redefinidos por ele, ou o retraduzem.

Destarte, a composição deste estudo, ao tomar os conceitos supracitados e suas possíveis concepções, vislumbra no contexto a seguir sua inscrição e seu poder de conformação ao tema. Em outras palavras, o estudo, pautado por essa vertente metodológica, trata o fenômeno e os conceitos afins processando sua ressignificação, descortinando-os através de olhares (inter) disciplinares. 


\section{$\mathrm{O}$ acesso aos serviços de saúde como objeto}

Ferreira (2004, p.30) define o acesso como "ingresso, entrada; trânsito, passagem; avizinhação, aproximação, chegada; alcance”. Adequando uma perspectiva objetiva à lógica dos serviços de saúde, ela estaria intimamente relacionada à porta de entrada ou ao local de recepção ou acolhimento do usuário no momento de expressão de sua necessidade de saúde.

$\mathrm{Na}$ literatura relativa à Saúde Coletiva, há inúmeras referências sobre os múltiplos entendimentos do termo, não só o relacionado ao "acesso à saúde", como também ao "acesso aos serviços de saúde" e, ademais, à "utilização". Em consonância com a teoria subjacente que o abarca, o conceito, por exemplo, se sujeita à ideia de procura (em termos de quantidade de tempo dispendido) ou demanda por um bem denominado "boa saúde", ao considerar a depreciação do estoque inicial de saúde de um indivíduo e o consequente investimento através do consumo de cuidados em saúde (GROSSMAN, 1972). Relacionase também à oferta de bens e serviços de saúde e suas barreiras, cujo enfoque teórico é a equidade horizontal: igual acesso para igual necessidade de saúde (GODDARD; SMITH, 2001).

Nos anos 1950, principalmente nos países anglo-saxões, estudos abordavam o uso pela população de serviços de saúde - públicos ou privados - sob uma perspectiva comportamental do sujeito, por meio de avaliação de suas crenças, atitudes e valores. Até meados dos anos 1970, os estudos se atinham à avaliação do uso dos serviços de saúde primordialmente a partir de conceitos como oferta e demanda, ou ainda à perspectiva das características da população (renda familiar, cobertura de atenção por seguros de saúde no que concerne à atenção médica, etc.), abordagem respaldada na teoria econômica do comportamento do consumidor. A partir dos anos 70, passou-se a incorporar a distribuição e a organização dos sistemas de saúde.

Ainda na perspectiva do seu dimensionamento, um dos muitos olhares se refere, por exemplo, ao interacionismo simbólico. Entendido a partir das representações sociais da atenção à saúde e dos serviços de saúde ao desvelar uma tensão-contradição entre a realidade subjetiva e a realidade concreta dos sujeitos em ato, ele suscita a incorporação da aceitabilidade, que, em última análise, reforça o papel dos sujeitos e de suas representações (CARVALHO et al., 2007). Vale frisar que outras dimensões têm sido referidas na literatura, para as quais 
novas interpretações são delineadas a partir da identificação de outros atributos relacionados, tais como acessibilidade, disponibilidade e capacidade de compra.

Mas foi a partir da entronização da equidade enquanto princípio que permeia e direciona a efetivação do acesso a saúde e seus serviços, no sentido da satisfação das necessidades sociais dos cidadãos, que esses estudos abrangeram uma multiplicidade de dimensões específicas para sua interpretação ou explicação, tendo como substrato o direito à saúde (WHITEHEAD, 2000) e a oportunidade de escolha do indivíduo para galgar seu bem-estar (SEN, 1992).

Ainda em decorrência da diversidade de entendimentos sobre a definição de "acesso aos serviços de saúde", autores vêm criando e revisitando suas dimensōes por meio da (re)construção de modelos explicativos, por vezes também interpretativos.

Ao se incorrer na vertente da linha do tempo, sem ter a pretensão de realizar uma revisão sistematizada sobre o tema, e sim chamar a atenção para as mudanças paradigmáticas sobre o conceito e consequentes modelos teóricos, algumas abordagens serão dispostas, a seguir, para ilustrar e, ao mesmo tempo, introduzir o debate de interesse.

O clássico trabalho de Aday e Andersen (1974, p.209) já alertava para a imprecisão do conceito de acesso e apresentava uma proposta de modelo para seu estudo, que, partindo das políticas de saúde, traçava uma rede de variáveis que incluíam as características do sistema de saúde (recursos e organização) e da população em risco (predisposição, capacidades, as necessidades percebidas e avaliadas pelos profissionais de saúde), a utilização dos serviços de saúde e a satisfação dos consumidores. Para esses autores, a inter-relação extrapolava a ideia de que o conhecimento sobre acesso restringia-se a saber se aqueles que "precisam" conseguiriam entrar no sistema de saúde, e se a conjugação das diferentes variáveis permitiria informar mudanças nesse sistema e na dinâmica dos serviços (ADAY; ANDERSEN, 1981).

Ao agregarem ao modelo explicativo um conjunto de novas variáveis, os autores desvelam nova concepção do conceito, fruto de recontextualização e aprimoramento teórico, quando passam do acesso aos serviços de saúde para o acesso à saúde. Ou seja, o acesso deixa de representar apenas a entrada nos serviços e o recebimento de cuidados subsequentes e passa a incorporar a efetividade da atenção no que concerne a utilização e resultado no sentido da satisfação das reais necessidades de saúde (ANDERSEN, 1995). 
Dentre os vários modelos teóricos construídos, sejam as proposições de Giovanella e Fleury (1996, p.177), o modelo economicista, o sanitaristaplanificador, o sanitarista-policista e o das representações sociais, seja o elaborado e revisitado por Evans \&Sttodart (2003, p.371), ou o realizado por Grossman (1972, p.1), o conceito de acesso se diversifica como um direito à saúde que se expressa no cotidiano dos cidadãos, na relação entre acesso e questôes relativas às determinações sociais do processo saúde-doença, ou ainda o acesso como demanda por saúde e seu custo de oportunidade, passando a ser vislumbrado como categoria de análise. Isso porque a perspectiva de análise da relação do usuário ou consumidor com os serviços de saúde ou com os prestadores de serviços não considera apenas a acessibilidade à assistência médica, mas também o grau de ajuste entre as características dos recursos de atenção à saúde e as da população, bem como a influência de questóes socioculturais e econômico-financeiras.

\section{A interdisciplinaridade como direcionador do debate}

Entender a interdisciplinaridade na Saúde Coletiva pressupóe revisitar os primórdios da configuração do campo da saúde pública sob o ideal "bourdieuano" e sua passagem paradigmática para o campo da Saúde Coletiva. No que concerne a sua evolução, o campo se caracteriza por ser uma aglutinação contínua de saberes disciplinares advindos de diferentes campos científicos, que, interpostos, de acordo com conjunturas sociopolíticas, entre outros fatores, permitem uma (re)condução da sua trajetória a um só tempo epistemológica e política (NUNES, 2005).

Segundo Pombo (2008, p. 15), a interdisciplinaridade exige não só uma convergência de pontos de vista, atingindo camadas mais profundas da realidade cognoscível, mas também uma aproximação pensada tanto do lado do sujeito quanto do próprio objeto de investigação e sua complexidade.

A interdisciplinaridade também implica uma axiomática comum, um conjunto de axiomas relativo a um grupo de disciplinas conexas e as consequentes relações entre elas, definidas a partir de um nível hierárquico ocupado por uma delas, que atua como integradora e mediadora dos discursos e, por decorrência, como coordenadora do campo disciplinar. Isso ainda que o ideal preconizado seja uma inscrição horizontal nas relações de poder, onde prevaleça inclusive uma dada reciprocidade entre os campos implicados e cujo objetivo é uma fecunda aprendizagem mútua por recombinação, ou melhor, 
por uma decodificação de princípios e conceitos no que tange a determinada problemática (LUZ, 2009; ALMEIDA FILHO, 2005). A constituição de novas problemáticas na área da Saúde Coletiva demanda não apenas a inserção de diversas outras disciplinas teóricas, como também a mudança de estratégias de pesquisa na busca de uma síntese interdisciplinar.

A disciplina que conduziu o principal construto sobre o acesso até meados dos anos 70 foi a Economia, seguida da Política e do Direito, observando-se atualmente a busca de outros axiomas e, consequentemente, a interseção de outras disciplinas. Dentre as inúmeras disciplinas que compõem a Saúde Coletiva, a Antropologia talvez seja a que melhor contemple a necessária compreensão sobre a reprodução social dos sujeitos na busca da satisfação de suas necessidades de saúde, pois mostra o valor do conhecimento que nasce com a experiência e a vivência, na contextualização dos sujeitos, na compreensão das relações entre os processos saúde-doença e realidade social e na elaboração de formas de abordagem (MINAYO, 2006).

\section{A Economia como disciplina}

$\mathrm{O}$ acesso tem sido explorado privilegiadamente sob as dimensões da oferta, da demanda e das respostas dos serviços (eficiência), termos da Economia, tendo como eixo estruturante a ideia de consumo de serviços. É através da Teoria Microeconômica, enquanto orientadora do processo de tomada de decisão, bem como das análises da oferta e da demanda, que se compreendem os efeitos das variações das condições de mercado e da intervenção estatal. A teoria analisa, inclusive, a adução do comportamento das unidades econômicas individuais, aí incluídos os consumidores.

No contexto da consolidação da filosofia capitalista na sociedade, o mapeamento dos diferentes padrões de consumo dos indivíduos, e mesmo dos subgrupos populacionais, influencia a relação entre oferta e demanda. Ela depende do conhecimento dos consumidores acerca da oferta dos serviços e da percepção de suas necessidades, individuais ou da coletividade, as quais, no caso, podem estimular o entendimento, não de saúde per se, mas dos cuidados em saúde enquanto bens adquiríveis, configurando a relação como produtor/consumidor. Isso se dá principalmente se esses cuidados em saúde têm a si atrelada a relação escassez/ excedente quanto a sua variação de preço (GIOVANELLA; FLEURY, 1996). 
O conceito de oferta, ao ser vinculado à saúde ou aos cuidados em saúde, traduz-se por uma demanda não satisfeita, ou então como aquela que induz a uma demanda, ao evidenciar, por meio desse mercado, necessidades não sentidas pelos indivíduos (SANCHO, 2005). Ademais, ainda é possível pensá-lo como decorrência do processo de decisão clínica do médico, seja pela grande variedade de alternativas diagnósticas e terapêuticas profissionalmente aceitáveis, seja pela incerteza do profissional médico em relação à melhor alternativa, ou mesmo pela assimetria de informação na relação entre usuário/cliente e o profissional médico.

Da mesma forma, o conceito de demanda, entre tantas concepções, ora se traveste de necessidade, ao se conjuminar a necessidade sentida à expressa na direção do querer algo em vista de algum propósito, tendo no modelo do comportamento racional do consumidor seu substrato, ora pode ser identificada como oferta induzida, quando o indivíduo tem sobre si o exercício da influência de um especialista ou de um provedor de cuidados em saúde (SANCHO, 2005). Além disso, o conceito apresenta duas possibilidades de expressão: uma relacionada à capacidade de pagamento (willingness to pay), determinada pelo status socioeconômico e mais afinada com a perspectiva de sistemas de saúde não universalistas; outra, ao custo de oportunidade, quando um indivíduo, por exemplo, não procura serviços de saúde ao considerar que o tempo perdido significa menor ganho em termos de salário ou de capital.

Todavia, a equidade no campo da Economia tem sido abordada no sentido da existência de um trade-off em relação à eficiência alocativa, particularmente a Eficiência de Pareto, ${ }^{1}$ que sinteticamente expressa a impossibilidade, ou melhor, a não existência de uma alocação que melhore o bem-estar de uma pessoa e piore o de outra. Isso leva a que a equidade e a eficiência, ou se distanciem, traduzindose em iniquidade ou ineficiência, ou se aproximem, quando a equidade aduz sua condição vertical ao dispor sobre a disponibilidade desigual de bens para necessidades desiguais, propiciando a introdução de políticas focalizadas. Os teóricos da Economia que se imiscuíram na explicação ou interpretação do acesso à saúde ou aos serviços o fizeram através da formalização de modelos de demanda, ou seja, aqueles que têm como cerne a escolha do indivíduo (preferência na perspectiva da restrição orçamentária) ou a utilidade (ordenação das preferências a partir da análise das escolhas em função do bem-estar). 
Modelo paradigmático, e que se distingue da maioria dos demais desenhados, foi o construído por Grossman (1972, p. 224), ao tratar a saúde não como um mero investimento em capital humano (aumento da produtividade), e sim sob a perspectiva da busca por um produto - o tempo saudável. $\mathrm{O}$ autor, análogo ao que se denomina "seguro biológico" (CANGUILHEM, 1943), dispôs uma tese, qual seja: um indivíduo nasce com um dado "estoque inicial de saúde" e este se deprecia ao longo do tempo. É, então, necessária uma reposição desse estoque por meio de um investimento em saúde, ou seja, a aquisição em determinado(s) momento(s) de bens intermediários, também denominados derivadas da demanda (cuidados de saúde), no sentido de que esse "tempo saudável”, ao refletir uma "boa saúde", propicie ganhos e a aquisição de outros bens. O modelo não trata a saúde como um bem de consumo, mas como um bem de mérito.

A complexidade em relação à definição de necessidade em saúde leva a distintos enfoques: quasi-oferta (econômica), para o qual a necessidade existe até que seja ofertado um tratamento eficaz; necessidade como demanda, para o qual o julgamento, independentemente de quem a avalie, é a variável que a permeia; ou como um conceito estruturante da equidade na atenção à saúde, quando abarca dimensões como condição de vida, tecnologias disponíveis, vínculos e autonomia (CECÍLIO, 2001).

O conceito de necessidade vis-à-vis o da demanda por serviços ainda é um dilema para os decisores da saúde. As necessidades são dadas pela percepção de um indivíduo doente ou incapacitado, enquanto a demanda por cuidados em saúde advém da necessidade de um sujeito que deseja receber esse cuidado e a utilização do serviço quando há efetivação da atenção. Entretanto, a necessidade não é necessariamente expressa como demanda, e a demanda não é necessariamente seguida da utilização. Além disso, é possível haver demanda e utilização sem uma real necessidade.

Diante do conjunto de ideias cotejadas, depreende-se que a incursão do arcabouço teórico da Economia na área da saúde, especificamente o axioma da racionalidade - para o qual o consumidor ou usuário é sempre capaz de definir ou escolher uma alternativa - não é aplicável ao acesso aos serviços de saúde, seja do ponto de vista da lógica do "véu da ignorância" (RAWLS, 1971), seja no aspecto do real desconhecimento tanto das necessidades de saúde quanto da 
disponibilidade de bens e serviços relativos ao setor. É, contudo, identificável que o discurso que permeia a disciplina permite vislumbrar a ressignificação dos conceitos de acordo com a interação disciplinar na vertente de suas práticas, em vista de distintos interesses socialmente construídos.

\section{A Política e o Direito como disciplinas}

Os pontos de vista da Política e do Direito sobre o acesso aos serviços de saúde têm em comum tópicos como o direito à saúde e a equidade. A pauta axiológica é dada pela justiça social ao considerar uma distribuição desigual entre a população das próprias necessidades de saúde.

A Política de Saúde, como disciplina, abrange o estudo das relações de poder, da formulação, condução, implementação e da [sua] análise ao discutir o papel do Estado, a relação entre este e a sociedade e as propostas e prioridades para a ação pública no que se refere às condições de saúde da população e seus determinantes. Por decorrência, a disciplina exterioriza sua interface com as políticas econômicas e as sociais. Suas práticas estão, enquanto açōes governamentais, dirigidas ao coletivo, supondo-o campo estruturado de práticas sociais ao produzir, distribuir, gestar e regular bens e serviços que afetam a saúde humana e o ambiente (PAIM; TEIXEIRA, 2006).

Tomando a questão sob a vertente política, o acesso à satisfação das necessidades de saúde só se dará caso a provisão desses serviços seja decorrente da ação concreta e responsável do Estado, ou seja, caso este providencie condiçôes e recursos necessários para este fim e, ao mesmo tempo, entronize o ideal de que a saúde é direito de todos os indivíduos reconhecidos e legitimados como cidadãos, portadores de direitos e deveres iguais, independentemente das iniquidades e desigualdades sociais que os diferenciem.

De acordo com o tipo de política adotada, emergem diferentes modelos de Estado: o neoliberal, relacionado à utilidade econômica dos indivíduos, ao ser regulado pelo mercado, atuando de forma residual e compensatória com políticas voltadas para os pobres; e o Social Democrata, relacionado à utilidade social dos indivíduos, atuando de forma residual pelas organizaçôes da sociedade e pelo mercado com políticas compensatórias sobre os pobres. Em termos conceituais, as diferenças residem no fato de o modelo neoliberal adotar a utilidade econômica dos indivíduos e o modelo social democrata legitimar a utilidade social do 
indivíduo, e de ambos partirem do princípio de que o Estado deve ser mínimo e se ater a ações regulatórias e compensatórias, ao definir o poder operativo das organizações intermediárias, que, por delegação, oferecem serviços para atender às necessidades em saúde das populações (JESUS; ASSIS, 2010).

A oferta estaria - até como consequência da ação política do Estado e, se balizada ao tema em questão - relacionada à organização do atendimento, ao cardápio de procedimentos oferecidos na rede assistencial, à rede de referência e contrarreferência e à complexidade tecnológica dos níveis de atenção com vistas à integralidade. Isso certamente advém de uma ideologia política das instituições, que levam em consideração a localização geográfica, a cultura médica local e a disponibilidade de serviços e de recursos (financeiros, humanos e tecnológicos).

A discussão sobre a oferta perpassa o Direito quando recai na igualdade de recursos, para a qual é requerida uma distribuição sensível às escolhas que as pessoas realizam, porém insensível às circunstâncias. Parte-se da posição fundamental de que, ausentes as diferenças imputáveis às escolhas das pessoas, a distribuição de recursos em uma sociedade em princípio deve ser igual. A disciplina está presente também quando se aborda a equidade de oportunidade (TURNER, 1986), ao afirmar-se que todos os indivíduos, independentemente de sua origem, têm as mesmas oportunidades de alcançar as mais altas posições individuais. Transposta para o setor saúde, essa proposição estaria relacionada a um indicativo de disponibilidade de recursos, dada a garantia da universalidade dos direitos à saúde para todos que têm a mesma condição de vida. Mas, se política de saúde se inscreve no ideal do bem público socialmente distribuído, o objetivo é buscar a concretização da efetividade das ações de saúde, entendendo que as práticas se dão sobre e no coletivo.

No que tange ao acesso aos serviços e na perspectiva das necessidades de saúde, dá-se interessante contradição, denominada "medical iceberg" (BECK, 1973): a necessidade ditada pelo profissional, em larga medida, só é (re)conhecida pelo indivíduo caso este tenha realmente acesso ao serviço de saúde. Do ponto de vista da demanda, a partir de uma necessidade sentida, o cuidado em saúde poderá ou não estar acessível, enquanto que as necessidades não percebidas só poderão ser "descobertas" por meio de um modelo de atenção ou de uma política de saúde que propicie, e ao mesmo tempo condicione, a demanda a partir da difusão de informações mais sistematizadas. 
De qualquer sorte, a busca dos indivíduos no sentido da realização de suas necessidades também pode ser enfocada sob uma diferente perspectiva política. Após revisão e crítica às diferentes concepções sobre necessidades de saúde, e ancorada na "deliberação democrática", cujo princípio é a decisão baseada em consenso, onde a deliberação ou participação permeia o processo de decisão pressupondo a construção de sujeitos políticos e politizados, postula-se que, diferentemente da ideia de a necessidade ser tomada como satisfação strictu sensu, esta se atrela às condições pelas quais foram julgadas a definição, a interpretação e a satisfação dessa necessidade (PETER, 2005).

Ou seja, a construção do acesso se dá pela participação cidadã e pelo controle social, que, intervindo na realidade das práticas e na gestão política, busca superar a racionalidade hegemônica ao conduzir uma ruptura que leva a uma nova realidade calcada no controle da sociedade. Nesse sentido, o acesso não é interferido pelas dimensões da oferta e demanda, mas sim pela indução à constituição de uma rede de atenção à saúde capaz de responder ao passivo social em saúde (GIOVANELLA; FLEURY, 1996).

Termos como "igualdade", "justiça social", "moral", "direitos humanos e sociais" estão intimamente relacionados à atual ideia de equidade, um princípio ético. A Ética, campo filosófico que elabora reflexões sobre os fundamentos morais, trata do terreno dos valores. Isso leva a que as formas desses valores, de acordo com seus respectivos contextos históricos e sociais, como um desafio para a prática, assumam nos distintos momentos as diferentes características das ditas necessidades sociais de saúde (LUIZ, 2005).

Do ponto de vista conceitual, o tema da equidade está longe de um consenso. Diferentes concepções alimentam as teorias sobre justiça social desenvolvidas pelas diversas correntes de pensamento. Cabe lembrar que as opçóes conceituais, inerentes aos desenhos de sistema de saúde, orientam a escolha dos critérios distributivos.

Pontuar a equidade em relação ao acesso supõe introduzir o princípio da diferença e as noções de igualdade e justiça: igualdade em referência à distribuição de bens no sentido de diminuição das diferenças, reconhecendose, em alguma medida a existência de lutas sociais, a participação popular e a ocorrência de cidadanias diferenciadas; e justiça em referência ao acesso a bens e direitos essenciais a partir da distribuição de capacidades (capabilities) básicas aos 
indivíduos (SEN, 1992). Ou seja, a equidade é a introdução da diferença no espaço da igualdade e a eliminação das desvantagens, criando justas oportunidades.

A equidade, respaldando a noção de que o acesso aos serviços de saúde não se inscreve enquanto uma situação injusta, desnecessária, indesejável e evitável, reflete, ao contrário, uma condição de empoderamento na busca pela cidadania. $\mathrm{O}$ acesso aos serviços de saúde, mais do que uma mera busca pela resolução dos problemas relativos à doença, é, numa perspectiva de justiça, uma adequada e satisfatória resolução das necessidades, mesmo que, vale lembrar, nem todas as diferenças sejam inevitáveis e inaceitáveis. Estas dependem, em geral, da liberdade de escolha do indivíduo ao se submeter a situações de risco.

Pode-se tomar o conceito desenvolvido para equidade em saúde como a ausência de diferenças sistemáticas em um ou mais aspectos do status de saúde nos grupos e subgrupos populacionais definidos social, demográfica e geograficamente, e também a equidade nos serviços de saúde como a não existência de diferenças onde as necessidades sejam as mesmas (equidade horizontal) ou então onde estejam as maiores (equidade vertical) (STARFIELD, 2002). Assim, é viável supor que a necessidade em saúde não deve ser configurada como o pilar estruturante da equidade, mas ter a si atreladas outras dimensões como a condição de vida, as tecnologias em saúde disponíveis e a autonomia do sujeito (aí incluída a necessária equidade em relação às informações referentes ao processo saúde-doença do sujeito). Entender, no entanto, o inerente juízo de valor sobre a equidade e sua relação com a igualdade e a justiça pressupõe identificar os eixos temáticos sob os quais os conceitos se assentam.

O conceito de equidade, que permeia o cerne da relação entre acesso e satisfação das necessidades de saúde e que tem a si vinculado um julgamento que associa igualdade e justiça, traz à tona sua inscrição no eixo da Filosofia do Direito, à qual está associada a concepção de igualdade material, baseada na redução das diferenças materiais existentes entre as pessoas, e não naquela concernente a uma divisão idêntica de recursos, que, em grande medida, pode reforçar a desigualdade. Convém lembrar que as desigualdades materiais atribuídas às circunstâncias, e não às escolhas dos indivíduos, são injustificáveis, até porque - já introduzindo o eixo da filosofia política - a questão passa a ser a relativização entre a criação, se é que possível, de igualdade de situação social, política e econômica sem infringir na liberdade (para a qual a escolha/preferência do indivíduo é levada 
em consideração) cuja igualdade de situação, para ser equitativa, pressupõe uma correção com medidas redistributivas (BLACKBURN, 1997).

No eixo da filosofia moral, a equidade, se relacionada à ideia de merecimento quando evocada a partir da concepção de justiça no sentido rawlsiano, é a possibilidade de um direito ao acesso a bens considerados essenciais, entre os quais os serviços de saúde (BEAUCHAMP, 2002). Compreender então a ressignificação do conceito de equidade no enfoque "em saúde" e "nos serviços em saúde" é primordial enquanto princípio, orientador de políticas e, por conseguinte, provedor de bens e serviços no sentido da redução das desigualdades sociais e na perspectiva de um processo em permanente transformação, fruto de uma intervenção sobre situações de conflito. Em outras palavras, enquanto um instrumento de justiça.

\section{As disciplinas da vertente da Socioantropologia}

O estudo das representações sociais em saúde e da Antropologia mostra que o processo saúde-doença é permeado de elementos culturais e sociais, sendo compreendido e vivenciado diferentemente pelos vários atores da sociedade.

Considerando que o acesso advém primordialmente de uma demanda do sujeito em ato, ou seja, daquele que, empoderado, percebe seu direito à saúde ou ao seu bem-estar a partir de uma necessidade sentida, a demanda per se, enquanto conceito, adquire importância no dimensionamento da categoria acesso à saúde e aos serviços. A demanda, se relativizada às necessidades de saúde - percebidas ou sentidas, não percebidas ou não sentidas, reais ou mesmo invisíveis -, deve escrutinizar a elaboração de políticas de saúde consubstanciadoras ou redistributivas de recursos implicados na obtenção de melhora ou de mudança no estado de saúde, e ainda ser examinada a partir de interpretações e percepções no cotidiano dos atores sociais e suas relações com a oferta no âmbito dos sistemas de saúde.

Entre a identificação do problema e a motivação para buscar algum tipo de atenção; entre as barreiras encontradas pelos indivíduos para acessar os serviços de saúde e as dificuldades no acolhimento de suas necessidades; entre as proposições das políticas e protocolos e as possibilidades práticas na sua implementação, perpassa uma complexa e dinâmica rede envolvendo diferentes interaçôes entre atores, protocolos de tratamento, fluxos, políticas e normas culturais e sociais. A literatura revela que, nos primórdios da avaliação sobre o comportamento do 
sujeito frente à busca por atenção às suas necessidades, este se atinha à vertente utilitarista, baseada na crença inquestionável do modelo biomédico.

As discussões sobre acesso sob o prisma do direito à atenção ou de seus aspectos simbólicos - vertente pouco explorada -, ao ressaltarem o conceito de representações sociais, cujo mote é o conhecimento das concepçōes sobre saúde e doença da população, podem subsidiar diferentes modos de intervenção ao visarem garantir a entrada do usuário no sistema de saúde (GIOVANELLA; FLEURY, 1996).

Ainda no bojo da dimensão simbólica, e com o intuito de detectar as necessidades invisíveis dos sujeitos, Campos (1993, p.191), ao discutir a utilidade dos inquéritos, aponta a importância das informações como representações de atitudes diante da doença, da utilização de serviços, da aceitação destes, e da existência de doenças autopercebidas, estabelecendo como decorrência um nexo de proximidade com a realidade subjetiva da sociedade no tocante à viabilização do acesso à saúde.

No entanto, para que esse olhar se configure como paradigma, referendando uma ressignificação conceitual do paradigma utilitarista para o da interpretação compreensiva, é imprescindível a formalização de estudos empíricos, pelos quais se corrobore, inclusive, a hipótese da busca por outros determinantes do processo saúde-doença-cuidado. Já em 1970, estudos etnográficos, ao observarem diferentes grupos sociais, sugeriam a inclusão de outros fatores à interpretação comportamental no que concerne à procura dos serviços de saúde (KLEINMAN, 1980).

\section{Consideraçōes finais e conclusão}

Ainda que alcançando diferentes perspectivas, as abordagens sobre o acesso à saúde seguem a racionalidade científica moderna de segmentação e naturalização dos fenômenos, comum nos estudos oriundos do planejamento em saúde e inspirada nas abordagens teóricas da economia política e neoclássica, levando a que por vezes se ignore a complexidade da sua produção e de suas interações (PINHEIRO; GUIZARDI; MACHADO; GOMES, 2005).

Sem caber aqui uma crítica do ponto de vista epistemológico, o questionamento recai sobre a lógica que informa os modos de apreensão e respostas aos obstáculos que se interpõem à saúde. Ainda que busque superar a ideia de "contrário de doença" (CAMARGO JR., 2004), o atual conceito de saúde tem ensejado majoritariamente abordagens compartimentalizadas, por referência às dimensões físicas, mentais e sociais, isoladamente. É importante, nessa medida, 
valorizar a emergência de uma nova proposição de concepções para saúde, doença e determinantes, as quais permitirão assumir o risco de transformar democraticamente o sistema de atenção à saúde e, ao mesmo tempo, a sociedade. A saúde não é um contínuo que vai do bem-estar à morte, mas sim um conceito socialmente construído, que leva em conta a perpétua tensão entre a adaptação da vida, o ambiente, a doença e a felicidade (CONTANDRIOPOULOS, 1999).

Assimilar a população como "consumidora de serviços" parece ser outro aspecto nevrálgico na discussão sobre acesso. Por esse ângulo, todo o conhecimento sobre a demanda, o sistema de saúde e a população adquire caráter meramente instrumental, de criação de estratégias visando a finalidades técnicas - da simples oferta de serviços à otimização dessa oferta, sob uma lógica de custo e benefício que, de certa forma, excluiria do processo os destinatários dessas intervenções.

Em uma perspectiva compreensiva, ao lançar algumas balizas indicando que os sujeitos sociais estabelecem ao longo de sua existência significados, intencionalidades e teorias explicativas sobre o mundo e as estruturas sociais, traz-se à tona o fato de o pesquisador, ainda que revestido do método científico, não ser o único que produz explicações e análises dos fatos sociais (MINAYO, 2006). As análises dos sujeitos sociais não podem ser ignoradas, mas sim reconhecidas como portadoras de racionalidade e analisadas à luz das conexões histórico-sociais que conformam tais discursos.

A proposição do adensamento do conceito de acesso aos serviços de saúde considera o deslocamento do sentido de barreira, enquanto entidades ou fatores tratados isoladamente, para as proposições de sínteses, do quadro da vulnerabilidade (AYRES, 2009).

Contudo, e independente do "descortino" do acesso aos serviços de saúde nas mais diferentes perspectivas, cabe ao Estado a interlocução com os destinatários das intervenções de saúde e sua inclusão nos sistemas sanitários, mesmo que esse Estado não seja hoje viável, numa perspectiva gramsciana, e que a política de saúde, ao se inscrever numa faixa em que a essencialidade dos bens e serviços justifique a ação desse Estado, de modo a prover os meios para a sua produção. A saúde, nessa medida, está na confluência entre um bem público e um bem meritório, e o Estado, diante desse fato, não deve participar da transformação dos pobres e incapazes em externalidades. Ou seja, é ele quem, em última instância, opera a democratização do acesso (DAIN, 2000). ${ }^{2}$ 


\section{Referências}

ADAY. L.A.; ANDERSEN, R.M. A framework for the study of access to medical care. Health Services Research, v.9, n.3, p.208-220, 1974.

. Equity of access to medical care: a conceptual and empirical overview. Medical Care, v.19, n.12, supl., p.4-27,1981.

ALMEIDA FILHO, N. Transdisciplinaridade e o paradigma pós-disciplinar na saúde. Saúde Soc., v.14, n.3, p.30-50, 2005.

ANDERSEN, R.M. Revisiting the behavioral model and access to medical care: does it matter? J Health SocBehav, v.36, n.1, p.1-10, 1995.

ANDERSON, J.G. Health Services Utilization: framework and review. Disponível em: http://www.ncbi.nlm.nih.gov/pmc/articles/PMC1071757/pdf/hsresearch00564-0011.pdf. Acesso em: 21 nov 2011.

ASSIS, M.M.A.; VILLA, T.C.S.; NASCIMENTO, M.A. Acesso aos serviços de saúde: uma possibilidade a ser construída na prática. Ciênc. Saúde Coletiva, v.8, n.3, p.815-823, 2003.

AYRES, J.R.C.M. et al. Risco, vulnerabilidade e práticas de prevenção e promoção da saúde. In: CAMPOS, G.W.S. et al. (Orgs). Tratado de Saúde Coletiva. São Paulo: Hucitec, 2009. p. 375-418.

BEAUCHAMP, T.L.; CHILDRESS James F. Princípios de ética biomédica. São Paulo: Loyola, 2002. p.352

BECK, R.G. Economic class and access to physician services under public medical care insurance. Intl J. Health Serv., v.3, p.341, 1973.

BLACKBURN, S. Dicionário Oxford de Filosofia. Rio de Janeiro: Jorge Zahar, 1997. 437p.

CAMARGO JR, K.R. Epistemologia numa hora dessas? (Os limites do cuidado). In: PINHEIRO, R.; MATTOS, R.A (Orgs.). Cuidado: as fronteiras da integralidade. Rio de Janeiro: Cepesc, 2004. p.157-70.

CAMPOS, C.E.A. Os inquéritos de saúde sob a perspectiva do planejamento. Cad Saude Publica, v.9, n.2, p.190-200, 1993.

CARVALHO, L.S. et al. O Interacionismo Simbólico como fundamentação para pesquisas de enfermagem pediátrica. R Enferm UERJ, Rio de Janeiro, v.15, n.1, p.119-24, 2007.

CANGUILHEM, G. Le normal e le pathologique. Paris: Presses Universitaires de France, 1943. $224 \mathrm{p}$

CECÍLIO, L.C.O. As necessidades de saúde como conceito estruturante na luta pela integralidade e eqüidade na atenção em saúde. In: PINHEIRO, R.; MATTOS, R.A. (Orgs). Os sentidos da integralidadena atenção e no cuidado à saúde. Rio de Janeiro: Cepesc, 2001. p. 113-26. 
CONTANDRIOPOULOS, A-P. La salud entre las ciencias de la vida y las ciencias sociales. Cuad Med Soc., v.77, p.19-33, 1999.

DAIN, S. Do Direito Social à Mercadoria. 2000. 190p. Tese (Concurso para Professor Titular) - Instituto de Medicina Social, Universidade do Estado do Rio de Janeiro, Rio de Janeiro, 2000.

DALGREN, G.; WHITEHEAD, M. Policies and Strategies to promote social equity in health. Institute for Future Studies. Disponível em: http://www.framtidsstudier.se/filebank/ files/20080109\$110739\$fil\$mZ8UVQv2wQFShMRF6wT.pdf. Acesso em: 21 nov 2011.

EVANS, R.G.; STODDART, G.L. Consuming research, producing health? American Journal of Public Health, v.93, n.3, p.371-79, 2003.

FERREIRA, A.B.H. Novo Dicionário da Língua Portuguesa.3 ed, Curitiba: Positivo, 2004. 607p. GERHARDT, T.E. Itinerários terapêuticos em situações de pobreza: diversidade e pluralidade. Cad. Saúde Pública, v.22, n.11, p.2449-2463, 2006.

GIOVANELLA, L.; FLEURY, S. Universalidade da Atenção à Saúde: acesso como categoria de análise. In: EIBENSCHUTZ, C. (Org). Política de Saúde: o público e o privado. Rio de Janeiro: Fiocruz, 1996. p.177-198.

GODDARD, M.; SMITH, P.C. Equity of access to health care services: theory and evidence. Social Science and Medicine, v. 539, n.9, p.1149-1162, 2001.

GROSSMAN, M. The Demand for health: a theoretical and empirical investigation. National Bureau of Economic Research Occasional Paper 119. New York: Columbia University Press, 1972. p.1-38.

JESUS, W.L.; ASSIS, M.M.A. Revisão sistemática sobre o conceito de acesso nos serviços de saúde: contribuição do planejamento. Cienc.Saúde Coletiva, v.15, n.1, p.161-70, 2010.

KLEINMAM, A. Patients and healers in the context of culture. California: Regents, 1980. 433p.

LUZ, M.T. Complexidade do campo da Saúde Coletiva: multidisciplinaridade, interdisciplinaridade, e transdisciplinaridade de saberes e práticas - análise sócio-histórica de uma trajetória paradigmática. Saúde Soc., v.18, n.2, p.304-31, 2009.

LUIZ, O.C. Direitos e equidade: princípios éticos para a saúde $\operatorname{Arq} M e d A B C$, v.30, n.2, p.69-75, 2005.

MINAYO, M.C.S. O desafio do conhecimento. Pesquisa qualitativa em saúde. São Paulo: Hucitec, 2006. 406 p.

NUNES, E. Pós-graduação em Saúde Coletiva no Brasil: Histórico e Perspectivas. Physis: Rev. Saúde Coletiva. Rio de Janeiro, v.15, n.1, p.13-38, 2005.

PAIM, J.S.; TEIXEIRA, C.F. Política, planejamento e gestão em saúde: balanço do estado da arte. Rev Saúde Pública, v.40, n.esp, p.73-8, 2006. 
PETER, F. Health evaluation and interpretation of health needs. WHO Meeting on Ethical

Issues in Health Resource Allocation: Fairness and Goodness, Thiruvananthapuram, 2000. Disponível em: http://www.unibas.ch/witheo/fabienne/publication.html/?print=1 . Acesso em: 19 mar 2005.

PINHEIRO, R. et al. Demanda em saúde e direito à saúde: liberdade ou necessidade? Algumas consideraçôes sobre os nexos constituintes das práticas de Integralidade. In: PINHEIRO, R.; MATTOS, R.A. (Orgs). Construção social da demanda: direito à saúde, trabalho em equipe, participação em espaços públicos. Rio de Janeiro: Cepesc, 2005. p.11-27.

POMBO, O. Epistemologia da interdisciplinaridade. Revista do Centro de Educação e Letras da Unioeste, v.10, n.1, p.9-40, 2008.

POSSAS, M. Eficiência seletiva: uma perspectiva neo-schumpeteriana evolucionária sobre questōes econômicas normativas. Revista de Economia Política, v.24, n.1, p.73-94, 2004.

RAWLS, J. A theoryofjustice. Oxford: University Press, 1971. 538p.

STARFIELD, B. Acessibilidade e primeiro contato: a "porta”. In: STARFIELD, B. (Org.). Atenção primária: equilíbrio entre necessidades de saúde, serviços e tecnologia. Brasília: Unesco/Ministério da Saúde, 2002. p. 207-45.

SANCHO, L.G. Avaliação Econômica em Saúde: fundamentação teórica, abordagens e possibilidades à luz das Terapias Renais Substitutivas. 2005. 253p. Tese (Doutorado em Saúde Coletiva) - Instituto de Medicina Social, Universidade do Estado do Rio de Janeiro, Rio de Janeiro, 2005

SEN, A. Inequality reexamined. Oxford: Clarendon Press, 1992. 224p.

TRAVASSOS, C.; MARTINS, M. Uma revisão sobre os conceitos de acesso e utilização de serviços de saúde. Cad.Saúde Pública, v.2, supl 2, p.S190-S198, 2004.

TURNER, B.S. Equality. London: Ellis Horwood, 1986. 143p.

WHITEHEAD, M. The concepts and principles of equity and health.EUR/ ICP/RPD 414, 7734r, Geneva: WHO, 2000. Disponível em: http://salud.ciee.flacso.org.ar/flacso/ optativas/equity_and_health.pdf. Acesso em: 16 nov 2011.

\section{Notas}

${ }^{1}$ A análise normativa em Economia está baseada na relação entre bem-estar social e eficiência econômica. A eficiência alocativa, enquanto um dos conceitos de eficiência econômica, trata da aplicação do conceito de Eficiência de Pareto para uma economia competitiva. Ou seja, a Eficiência de Paretoexiste quando ocorre o denominado equilíbrio competitivo, onde cada agente econômico escolhe sua alocação preferida e a quantidade demandada se iguala à quantidade ofertada em cada um dos mercados. Em termos de bem-estar social, as alocações sociais são ordenáveis ou comparáveis quando a utilidade de pelo menos um agente (indivíduo) varia (melhora), sem que a de qualquer outro indivíduo varie 
em direção oposta. Em outras palavras, por definição, não são comparáveis em termos de Pareto duas situaçôes tais que a utilidade de alguém aumenta enquanto a de outrem diminui. (POSSAS, 2004). A política redistributiva, ao propor a transferência de recursos, leva a uma diminuição dos níveis de renda total e ao uso menos eficiente de recursos. Nessa medida, e no sentido de que não ocorra uma redistribuição que favoreça os que não necessitem, a melhor alocação é aquela que gere menor tradeoff. ${ }^{2}$ L.G. Sancho concebeu a ideia do estudo e da redação inicial e final do texto; N.E.K. Silva participou da redação inicial e final do artigo. 


\section{Abstract}

\section{Revealing access to healthcare services from an interdisciplinary perspective: some ideas}

This study aims to highlight through the interdisciplinary perspective of Economics, Politics, Law and Socioanthropology, the concept of access, particularly related to health care. We do not only consider the concept and redefinition of supply, demand, equity and health needs by arising from these disciplines, but also consider access regardless of public or private sector more than a question of supply; it must initially glimpse "invisible needs", in case we internalize the idea that the health-disease process does not include other determinants to be understood. Through literature review on national and international texts over the past five decades, we identified studies on the diversity of looks in relation to the object of study. According to different paradigms in a historical and contextual perspective, it was evidenced that understanding and realization of access to health care require interdisciplinary approaches; this endorses the State as provider of policies and organized actions that change health status and quality of life of the subject.

> Key words: access; health services; interdisciplinary; concept formation. 